\title{
Mixed-phase bismuth ferrite nanoflake electrodes for supercapacitor application
}

\author{
Vijaykumar V. Jadhav ${ }^{1,2,4} \cdot$ Manohar K. Zate ${ }^{1} \cdot$ Shude Liu $^{4} \cdot$ Mu. Naushad ${ }^{3}$. \\ Rajaram S. Mane ${ }^{1,2} \cdot$ K. N. Hui ${ }^{4}$ Sung-Hwan Han ${ }^{2}$
}

Received: 22 February 2015/ Accepted: 2 June 2015/Published online: 18 June 2015

(c) The Author(s) 2015. This article is published with open access at Springerlink.com

\begin{abstract}
Nanoflake bismuth ferrite thin film was synthesized by means of electrodeposition technique at room temperature. The morphology and phase evaluation of the synthesized electrode were analyzed using scanning electron microscopy, X-ray diffraction, Raman spectroscopy, and surface wettability techniques. Specifically, the bismuth ferrite nanoflake electrode exhibited high specific capacitance of $72.2 \mathrm{~F} \mathrm{~g}^{-1}$ at a current density of $1 \mathrm{~A} \mathrm{~g}^{-1}$, and high rate capability with $37 \%$ retention of capacitance even up to $20 \mathrm{~A} \mathrm{~g}^{-1}$, and excellent cycling stability with $82.8 \%$ retention of the initial capacitance after 1500 charge/discharge cycles, supporting that the bismuth ferrite thin-film electrode could be a potential candidate for supercapacitor application.
\end{abstract}

Keywords Electrodeposition - Nanostructure - Ferrite · Electrochemical supercapacitor

Rajaram S. Mane

rsmane_2000@yahoo.com

$凶$ K. N. Hui

bizhui@pusan.ac.kr

1 Center for Nanomaterials and Energy Devices, School of Physical Sciences, Swami Ramanand Teerth Marathwada University, Nanded 431606, MS, India

2 Inorganic Nanomaterials Laboratory, Department of Chemistry, Hanyang University, Seoul 133-1791, Republic of Korea

3 Advanced Materials Research Chair, Department of Chemistry, College of Science, King Saud University, Riyadh, Saudi Arabia

4 School of Materials Science and Engineering, Pusan National University, San 30 Jangjeon-dong, Geumjeong-gu, Busan 609-735, Korea

\section{Introduction}

Now-a-days, fast-growing market for portable electronic devices such as mobile phones, laptops, notebook computers, uninterruptible power supply, and the development of hybrid electric vehicles, etc., is increasing and there is an urgent demand for environmental-friendly high-power energy storage resources. Also rapid growth of research in the field of electrochemical energy storage systems has been driven by the increased development of nanostructured materials. Electrochemical supercapacitors have attracted great attention because of their ability to deliver high power and energy densities with outstanding cycling stability. A supercapacitor is an assuring energy storage device, which can function as a gap-bridging device between batteries and conventional capacitors (Chu and Majumdar 2012; Winter and Brodd 2004; Zhai et al. 2011). Supercapacitive performance of a material either in the form of a thin-film or of a pallet, used as an electrode can be assayed by cyclic-voltammetry (CV) and galvanostatic charge-discharge measurements. An electrode is judged by its specific capacitance value and the number of chargedischarge cycles it withstands, maintaining the constancy of capacitance. This brings forth the search for a wide variety of materials. In general, transition metal oxides, including $\mathrm{RuO}_{2}, \mathrm{MnO}_{2}, \mathrm{NiO}, \mathrm{Co}_{3} \mathrm{O}_{4}, \mathrm{SnO}_{2}, \mathrm{ZnO}, \mathrm{TiO}_{2}$, $\mathrm{V}_{2} \mathrm{O}_{5}, \mathrm{CuO}, \mathrm{Fe}_{2} \mathrm{O}_{3}$, and $\mathrm{WO}_{3}$ (Lang et al. 2011; Athoue et al. 2008; Yan et al. 2010; Chen et al. 2012; Luo et al. 2014; Liu et al. 2014; Sathiya et al. 2011; David et al. 2014; Brezesinski et al. 2009; Wang et al. 2013; Liang et al. 2010; Xia et al. 2014; Kang et al. 2013; Yu et al. 2014), etc., have demonstrated high specific capacitance values with their redox reaction behaviors.

Ferrites, a class of metal oxide-based materials, have been attracting great attention in energy storage device due 
to their important applications in electronic materials industries. Most fascinating applications of ferrite materials include antenna rod, transformer core, recording head, loading coil, memory, and microwave devices, etc. (Petzold 2003; Niesen and De Guire 2001; Yoshimura et al. 2000). The present day electronic industries move constantly toward miniaturization of devices, and development of new materials to replace the existing ones when their inherent technological limits have been reached. The field of smart multiferroics is the top research topic (Schileo 2013; Kuo 2013). Bismuth ferrite (BFO), one of the very few multiferroics with a simultaneous coexistence of parameters of both ferroelectric and antiferromagnetic orders in perovskite structure, has been attracting great attention over the past several decades. Potential applications of BFO in the memory devices, such as sensors, spintronic devices, satellite communications, optic filters, and smart devices, etc., are greatly limited due to its low insulation resistance caused by the reduction of $\mathrm{Fe}^{3+}$ species to $\mathrm{Fe}^{2+}$ and in oxygen vacancies for charge compensation (Wang et al. 2004; Martin 2010; Cheong and Mostovoy 2007). The preparation of single-phase BFO without impurities is a critical task due to its narrow temperature stability range (Jaiswal et al. 2010). Using conventional solid-state reaction routes, the preparation of $\mathrm{BFO}$ material faces following difficulties:

(a) It is difficult to develop the pure phase of BFO, i.e., $\mathrm{BiFeO}_{3}$, as while forming $\mathrm{BFO}$, other thermodynamically more stable phases such as $\mathrm{Bi}_{2 \mathrm{~F}} \mathrm{e}_{409}, \mathrm{Bi}_{46 \mathrm{~F}-}$ $\mathrm{e}_{2 \mathrm{O} 72}, \mathrm{Bi}_{25 \mathrm{~F}} \mathrm{eO}_{40}, \mathrm{Bi}_{24 \mathrm{~F}} \mathrm{e}_{2 \mathrm{O} 39}$, and $\mathrm{Bi}_{36 \mathrm{~F}} \mathrm{e}_{2 \mathrm{O} 57}$, etc, are generally dominant.

(b) In general, the platinum crucible is needed for its preparation, which can be used only for three or four times. This increases the sample preparation cost, and,

(c) during the deposition, the substrate must be placed at the elevated temperatures; therefore, this causes restrictions on the selection of the substrate material.

Single-phase BFO powder was prepared by oxide-mixing technique followed by leaching with dilute nitric acid to eliminate unreacted impurity phases (Kumar et al. 2000). Palkar and Pinto (2002) have reported the synthesis of highly resistive thin film of pure BFO phase using pulsed laser-deposition method. Epitaxial growth of BFO phase, i.e., $\mathrm{Bi}_{3} \mathrm{Fe}_{5} \mathrm{O}_{12}$, has been prepared by a reactive ion beam sputtering technique by Adachi et al. (2000). BFO nanostructures including nanofibers (Mohan and Subramanian 2013), nanowires (Das et al. 2013; Gao et al. 2006), nanorods (Xie et al. 2008), nanoparticles (Chen et al. 2006; Biasotto et al. 2011; Jadhav et al. 2013), microcubes, and nanoplates (Waghmare et al. 2012) have already been reported. These nanostructures are expected to offer better efficiency owing to their large surface areas giving rise to high values of specific capacitance. Electrodeposition is a powerful and interesting methodology that can be applied in numerous fields for synthesizing thin metal oxide/ chalcogenide thin films or coatings. It has been used for the preparation of thin and thick films of iron group metal oxides at relatively low temperatures (Sartale et al. 2004; Mo et al. 2000; Gujar et al. 2006). Lokhande et al. (2007) obtained BFO films with a specific capacitance of $81 \mathrm{~F} \mathrm{~g}^{-1}$ using electrodeposition method. Dutta et al. (2013) reported remarkably a high value of specific capacitance of 450 $\mathrm{F}^{-1}$ for BFO nanorods prepared by a wet chemical template method.

In the present study, BFO structures of mixed phases were synthesized onto conducting substrate using electrodeposition technique at room temperature. These electrodes were further envisaged for their structural elucidation and morphological confirmation studies. Different preparative parameters including the effective potential window, the $\mathrm{pH}$ of bath composition, and the temperature effects were optimized so as to get optimal supercapacitive performance. The mechanisms of reduction and oxidation reactions in the electrolyte were studied for different current densities and CV curves. The effects of bismuth nitrate and ferric nitrate concentrations on structural, morphological, surface wettability, and supercapacitive properties were explored. The effects of electrolyte concentration and scan rate on electrochemical properties of BFO were also investigated. In addition, charging-discharging, Raman analysis, and impedance characteristics of BFO electrodes were studied.

\section{Experimental}

\section{Sample synthesis and characterizations}

BFO thin film electrodes were prepared using analytic grade chemicals and double-distilled water. The bath solution was made up of $0.2 \mathrm{M}$ bismuth (III) nitrate (Bi $\left.\left(\mathrm{NO}_{3}\right)_{3} \cdot 5 \mathrm{H}_{2} \mathrm{O}\right)$, and $0.2 \mathrm{M}$ ferric (III) nitrate $\left(\mathrm{Fe}\left(\mathrm{NO}_{3}\right)_{3}\right)$ with $0.2 \mathrm{M}$ tartaric acid $\left(\mathrm{C}_{4} \mathrm{H}_{6} \mathrm{O}_{6}\right)$ as a complexing agent, and the $\mathrm{pH}$ value of $\sim 12$ was maintained through the addition of sodium hydroxide $(\mathrm{NaOH})$ aqueous solution. BFO thin films were electrodeposited onto precleaned SS substrate under galvanostatic mode using $\mathrm{CP}$ at $3 \mathrm{~mA}$ for $300 \mathrm{~s}$. At room temperature, electrodeposited sample was black in color. These films were then air annealed at 400, 500 , and $600{ }^{\circ} \mathrm{C}$ temperatures for $2 \mathrm{~h}$. Reddish films were seen with naked eyes on the SS substrate after annealing at 400 and $500{ }^{\circ} \mathrm{C}$. At $600{ }^{\circ} \mathrm{C}$, the sample again turned black in color. The mass of active BFO electrode material was around $1 \mathrm{mg} \mathrm{cm}^{-2}$. 
Fig. 1 Digital photoimages of mixed phase bismuth ferrites for different annealing temperatures
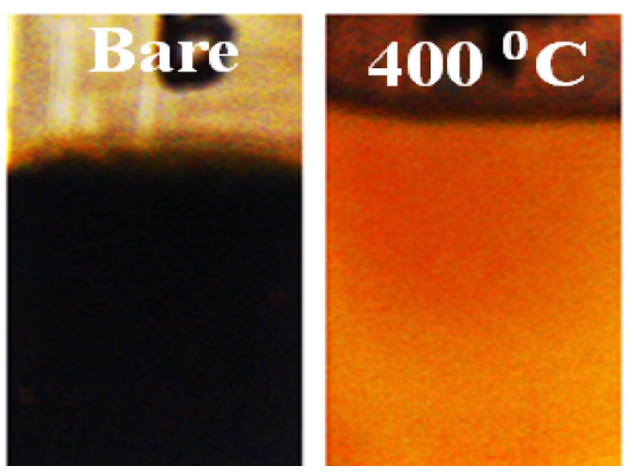

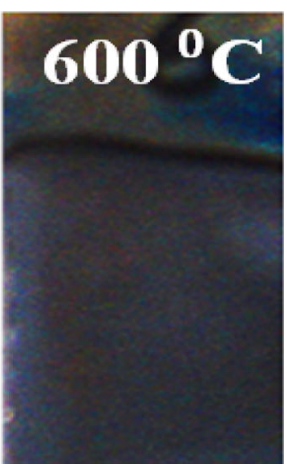

Mixed-phase BFO electrodes were examined for their morphologies and structures. X- ray diffractometer (Rigaku D/MAX $2500 \mathrm{~V}, \mathrm{Cu} \mathrm{K} \alpha, \lambda=1.5418 \AA$ ) was used for obtaining X-ray diffraction (XRD) spectra, and for evaluating surface morphologies, field-emission scanning electron microscopy (FE-SEM, Hitachi S-4200) images were recorded. Raman shift measurement was taken in order to confirm ferrite phase transformation with the increasing temperature. Contact angle measurements on as-deposited film electrode surfaces were carried out by sessile drop method, in which water drop was observed through a microscope-coupled goniometer (Phoenix 150, Surface Electro Optics, Korea). For electrochemical measurements, $1 \times 1 \mathrm{~cm}^{2}$ was defined as the active electrode surface area for each measurement in the presence of platinum $(\mathrm{Pt})$ as counter electrode and $\mathrm{Ag} / \mathrm{AgCl}$ as reference electrode in $1 \mathrm{M} \mathrm{NaOH}$. A frequency range of $0.01 \mathrm{~Hz}-1.5 \mathrm{MHz}$ and an amplitude of $50 \mathrm{mV}$ were applied during the EIS analysis.

\section{Results and discussion}

Figure 1 shows digital photoimages of BFO electrodes deposited onto SS substrate by means of electrodeposition method at room temperature, which were further annealed at 400,500 , and $600{ }^{\circ} \mathrm{C}$ temperatures. As seen in Fig. 1, the as-deposited films were black in color. After annealing at $400{ }^{\circ} \mathrm{C}$, the films turned reddish. At $500{ }^{\circ} \mathrm{C}$, the films turned into reddish yellow, and finally, at $600{ }^{\circ} \mathrm{C}$, the film surface was again black in appearance.

The XRD spectra of BFO electrodes synthesized and annealed at 400,500 , and $600{ }^{\circ} \mathrm{C}$ temperatures are presented in Fig. 2. BFO film annealed at $600{ }^{\circ} \mathrm{C}$ exhibited intense reflection peaks which correspond to $\mathrm{Bi}_{2} \mathrm{~F}_{4} \mathrm{O}_{9}$ structure. Most of the obtained (201), (211), (002), (221), (310), and (142) peaks were closely matching with $\mathrm{Bi}_{2} \mathrm{~F}_{4} \mathrm{O}_{9}$ phase of BFO (JCPDS card no. 25-0090). The lattice parameters were $a=7.96 \AA, b=8.44 \AA, c=5.99 \AA$ with orthorhombic $\mathrm{Bi}_{2} \mathrm{~F}_{4} \mathrm{O}_{9}$ type crystal structure. Secondary $\mathrm{BiFeO}_{3}$ phase of $\mathrm{BFO}$ was noticed at $600{ }^{\circ} \mathrm{C}$ due to

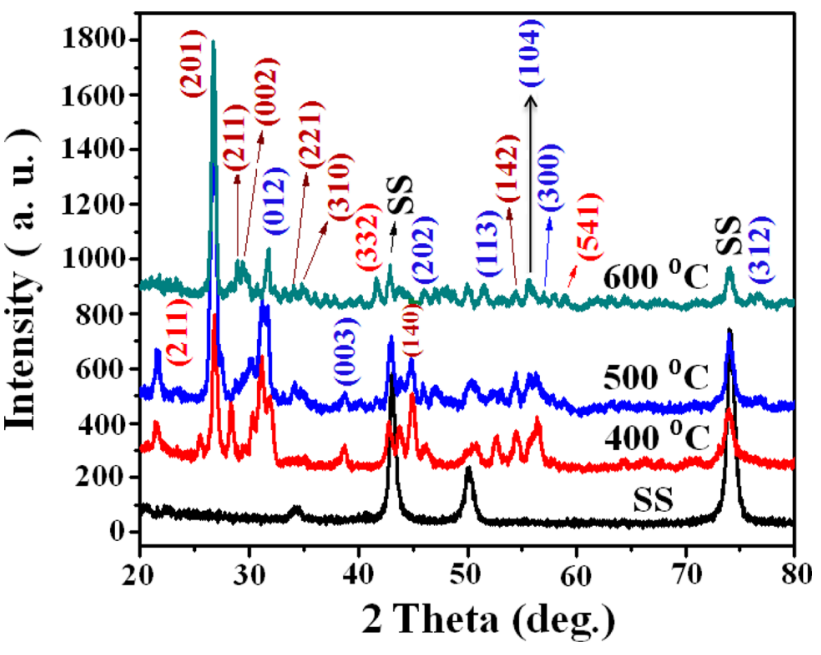

Fig. 2 XRD spectra of BFO electrodes annealed at 400, 500, and $600{ }^{\circ} \mathrm{C}$

occurrence of (012), (202), (113), (104), (300), (312) peaks (JCPDS Card no. 20-0169) in XRD pattern. The lattice parameters of $\mathrm{BiFeO}_{3}$ were $a=b=5.58 \AA, c=6.93 \AA$ with rhombohedral structure (Zheng et al. 2012). Ternary phase $\mathrm{Bi}_{25} \mathrm{FeO}_{40}$ was also confirmed in accordance with JCPDS card no. 46-0416 as there were only (211), (332), and (541) peaks. From XRD pattern, it was clear that $\mathrm{Bi}_{2} \mathrm{~F}_{4} \mathrm{O}_{9}$ phase was more dominant than $\mathrm{BiFeO}_{3}$ phase. Only two peaks were of $\mathrm{Bi}_{25} \mathrm{FeO}_{40}$. Hence, it was concluded that at $600{ }^{\circ} \mathrm{C}$, BFO phase cannot be supposed to have high crystallinity. Along with the formation of primary phase of BFO $\left(\mathrm{BiFeO}_{3}\right)$, secondary phase and ternary phases were also emerged (Singh et al. 2008; Perejon et al. 2014; Bernardo et al. 2011) as a function of annealing temeparture.

Surface morphologies of BFO electrodes annealed at 400, 500, and $600{ }^{\circ} \mathrm{C}$ for $2 \mathrm{~h}$ are shown in Fig. 3. It was concluded that by changing the electrodeposition composition/condition, the structural morphology can be greatly altered. From the FE-SEM imaging, the BFO electrode annealed at $400{ }^{\circ} \mathrm{C}$ revealed irregular flake-like structure. A few smaller crystallites of irregular dimensions were found on the surfaces. Morphology of BFO electrode 
Fig. 3 FE-SEM images of BFO electrodes annealed at 400, 500, and $600{ }^{\circ} \mathrm{C}$ and EDX spectra at $600{ }^{\circ} \mathrm{C}$

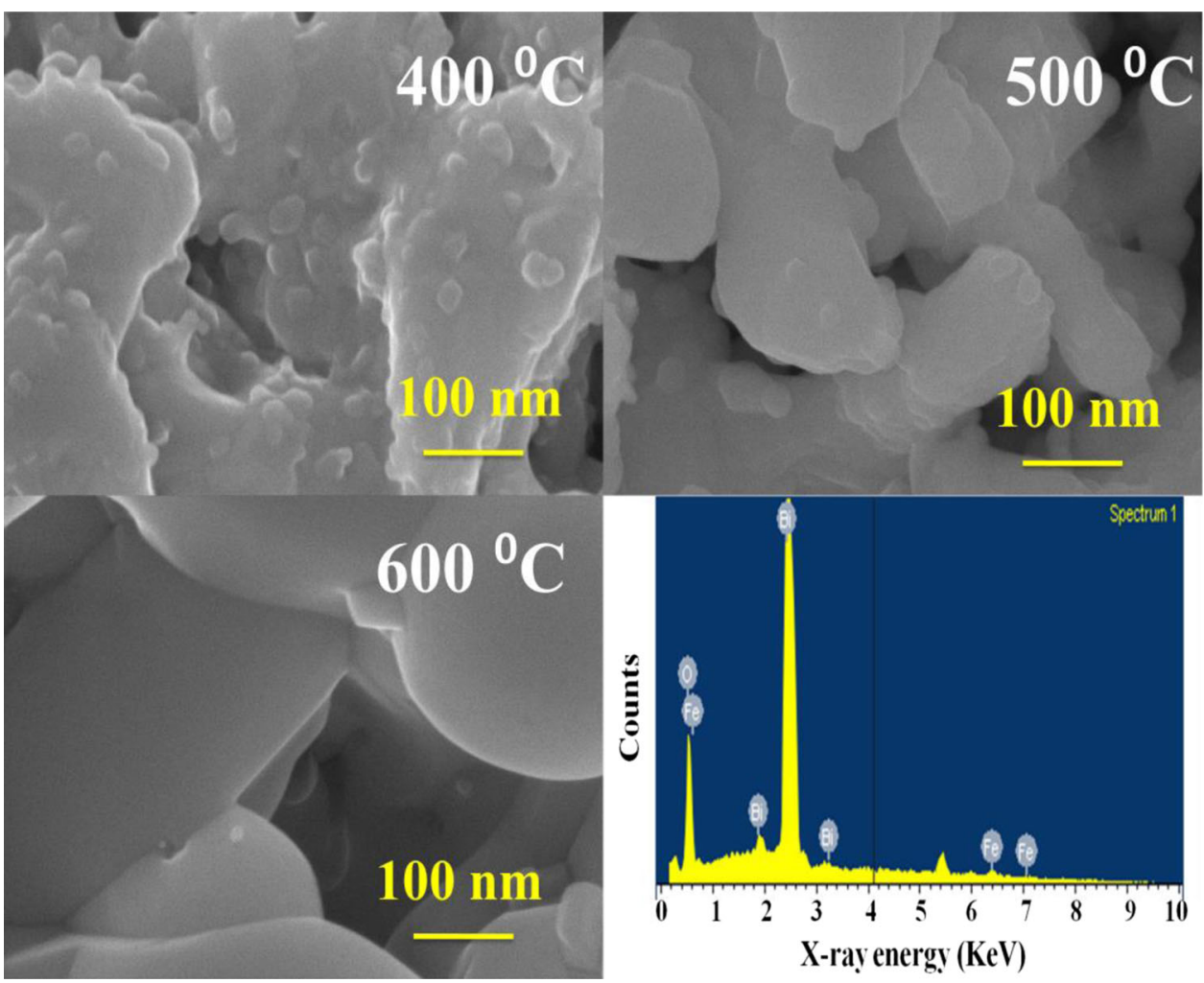

annealed at $500{ }^{\circ} \mathrm{C}$ showed a smooth and polished-type structure. Moreover, flakes were smaller in dimensions. A few numbers of smaller crystallites were seen on these flakes. At $600{ }^{\circ} \mathrm{C}$ annealing temperature, these flakes were polished-type structure. There were no small crystallites seen over the flakes as seen in other cases. Figure 3 shows the EDX pattern of BFO electrode deposited onto SS substrate, annealed at $600{ }^{\circ} \mathrm{C}$ for $2 \mathrm{~h}$, and the elemental analyses carried out for $\mathrm{Bi}, \mathrm{Fe}$, and $\mathrm{O}$. From the EDX pattern, the presence of $\mathrm{Bi}, \mathrm{Fe}$, and $\mathrm{O}$ elements in the electrodeposited BFO product in the ratio of $1: 2: 3$ was confirmed. Figure 4 shows Raman spectra with vibrational modes at 616, 663, 830, 821, 852, and $1327 \mathrm{~cm}^{-1}$. From Raman analysis it was clear that at $600{ }^{\circ} \mathrm{C}$, BFO phase formation was confirmed. The presence of only one Raman mode at 400 and $500{ }^{\circ} \mathrm{C}$ supported the fact that the temperatures below $500{ }^{\circ} \mathrm{C}$ were not adequate for the formation of ferrite structure. For the BFO obtained at $600{ }^{\circ} \mathrm{C}$, five Raman modes appeared suggesting the formation of ferrite structure.

The surface microstructure plays a vital role in the wetting properties of materials. The wetting behavior of surfaces is governed by both their chemical composition and geometric microstructure. If the surface wettability is high, contact angle $(\theta)$ will be small, and the surface is hydrophilic. On the contrary, if the wettability is low, $\theta$ will be large, and the surface is hydrophobic. Figure 5

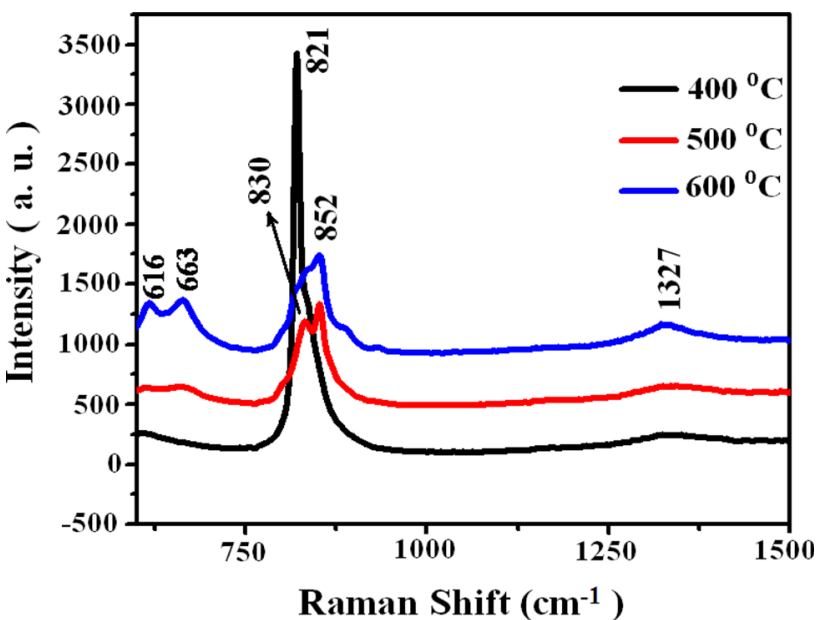

Fig. 4 Raman spectra of BFO electrodes annealed at 400, 500, and $600{ }^{\circ} \mathrm{C}$

presents water contact angle measurements on $\mathrm{BFO}$ electrode surfaces annealed at 400, 500, and $600{ }^{\circ} \mathrm{C}$ temperatures. Due to change in surface morphology, the contact angle was decreased from $86.21^{\circ}$ to $58.48^{\circ}$. With the increasing annealing temperature, water contact angle value was decreased. Lower contact could be beneficial for achieving enhanced specific capacitance (Mane et al. 2007; Sun et al. 2001; Conway and Pell 2002). 


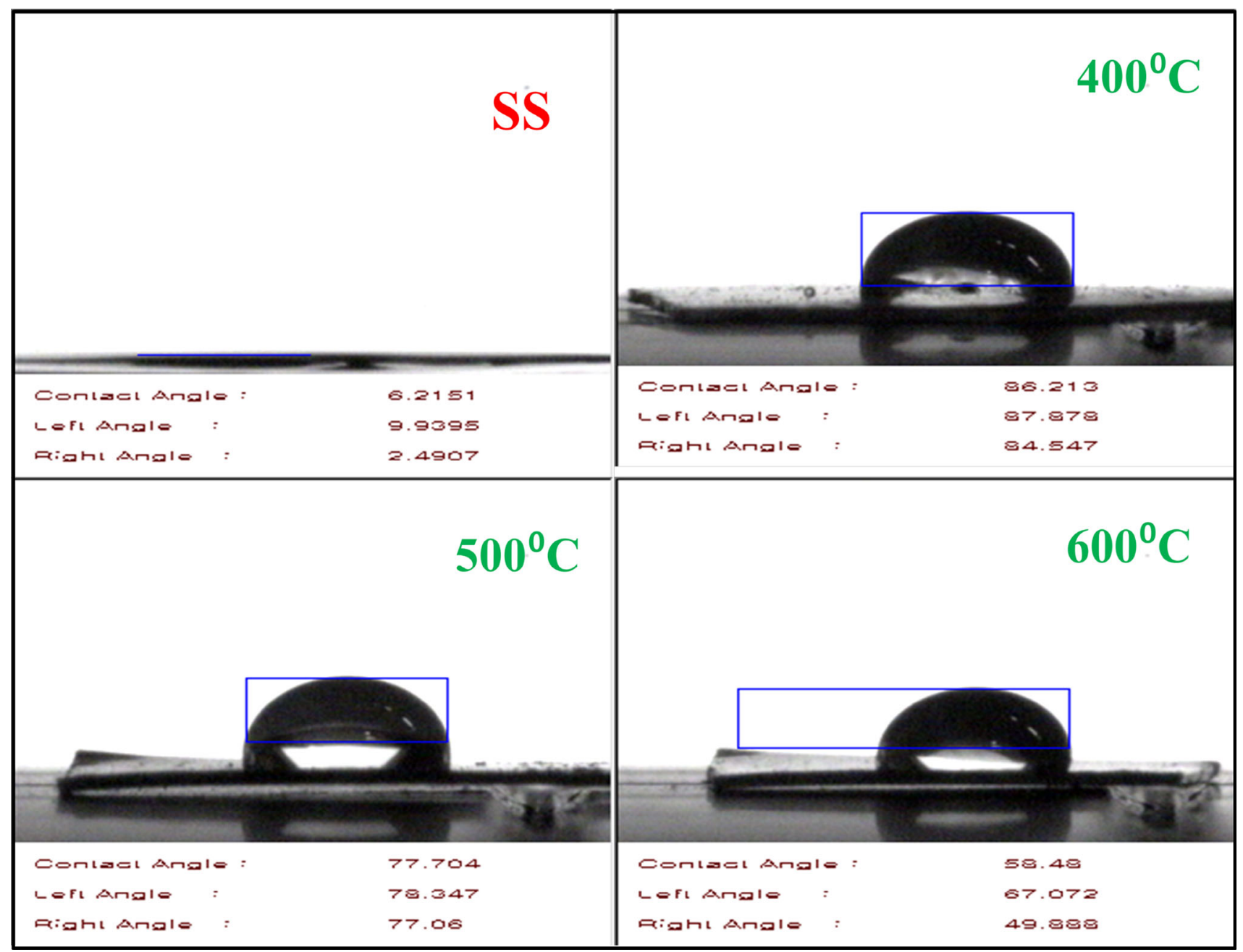

Fig. 5 Contact angle measurements on SS and BFO surfaces annealed at various temperatures

Cyclic voltammetry (CV) measurement was employed to explore the BFO electrodes for electrochemical supercapacitor application with $\mathrm{NaOH}$ electrolyte of different concentrations in a conventional three-electrode system.

Effect of scan rate on electrochemical supercapacitor performance of $\mathrm{BFO}$ electrode was studied in $0.25,0.5$, $0.75,1,1.5$, and $2 \mathrm{M} \mathrm{NaOH}$ electrolyte concetrations at the constant scan rate $10 \mathrm{mV} \mathrm{s}^{-1}$. Figure 6 represents $\mathrm{CV}$ curves of $\mathrm{BFO}$ electrodes in $\mathrm{NaOH}$ electrolyte of different concentrations. From the results, it was concluded that with the increasing concentration of $\mathrm{NaOH}$ electrolyte from 0.25 to $2 \mathrm{M}$, the $\mathrm{SC}$ value of $\mathrm{BFO}$ was increased. It was found that the BFO electrode annealed at $600{ }^{\circ} \mathrm{C}$ exhibited maximum current density which could be attributed to the formation of complete ferrite structure. This electrode was scanned for different scan rates in $2 \mathrm{M} \mathrm{NaOH}$, and the results are shown in Fig. $7 \mathrm{a}$. With the scan rate being increased from 10 to $1000 \mathrm{mV} \mathrm{s}^{-1}$, the SC value of BFO electrode was found to decrease from 101.63 to $5.65 \mathrm{~F} \mathrm{~g}^{-1}$, indicating that at lower scan rates, inner and outer sites were more active, and thus, full utilization of BFO electrode in $\mathrm{NaOH}$ electrolyte solution occured. Hence, this might help to increase the SC of BFO electrode at lower scan rate. At higher scan rates, only outer sites could be more active than inner sites which were unable to participate in the redox reaction in the electrolyte solution (Subramanian et al. 2004; Wang et al. 2012).

To further investigate electrochemical performances of the nanoflake BFO electrode, we perform galvanostatic charge-discharge (GCD) curves at various current densities in an electrochemical window from -0.8 to $0.2 \mathrm{~V}$ (Fig. 7b). There was a nontriangular symmetry and linear slopes, consolidating the good pseudocapacitive behavior. The capacitance within the voltage region mainly resulted from the reduction of $\mathrm{Fe}^{3+}$ species to $\mathrm{Fe}^{2+}$ and the presence of oxygen vacancies for charge compensation (Qin et al. 2011). The capacitance values of two electrodes at various current densities were calculated based 
Fig. $6 \mathrm{CV}$ curves of $\mathrm{BFO}$ electrode in; a $0.25 \mathrm{M}, \mathbf{b} 0.5 \mathrm{M}$, c $0.75 \mathrm{M}$, d $1 \mathrm{M}$, e $1.5 \mathrm{M}$, f $2 \mathrm{M}$ $\mathrm{NaOH}$
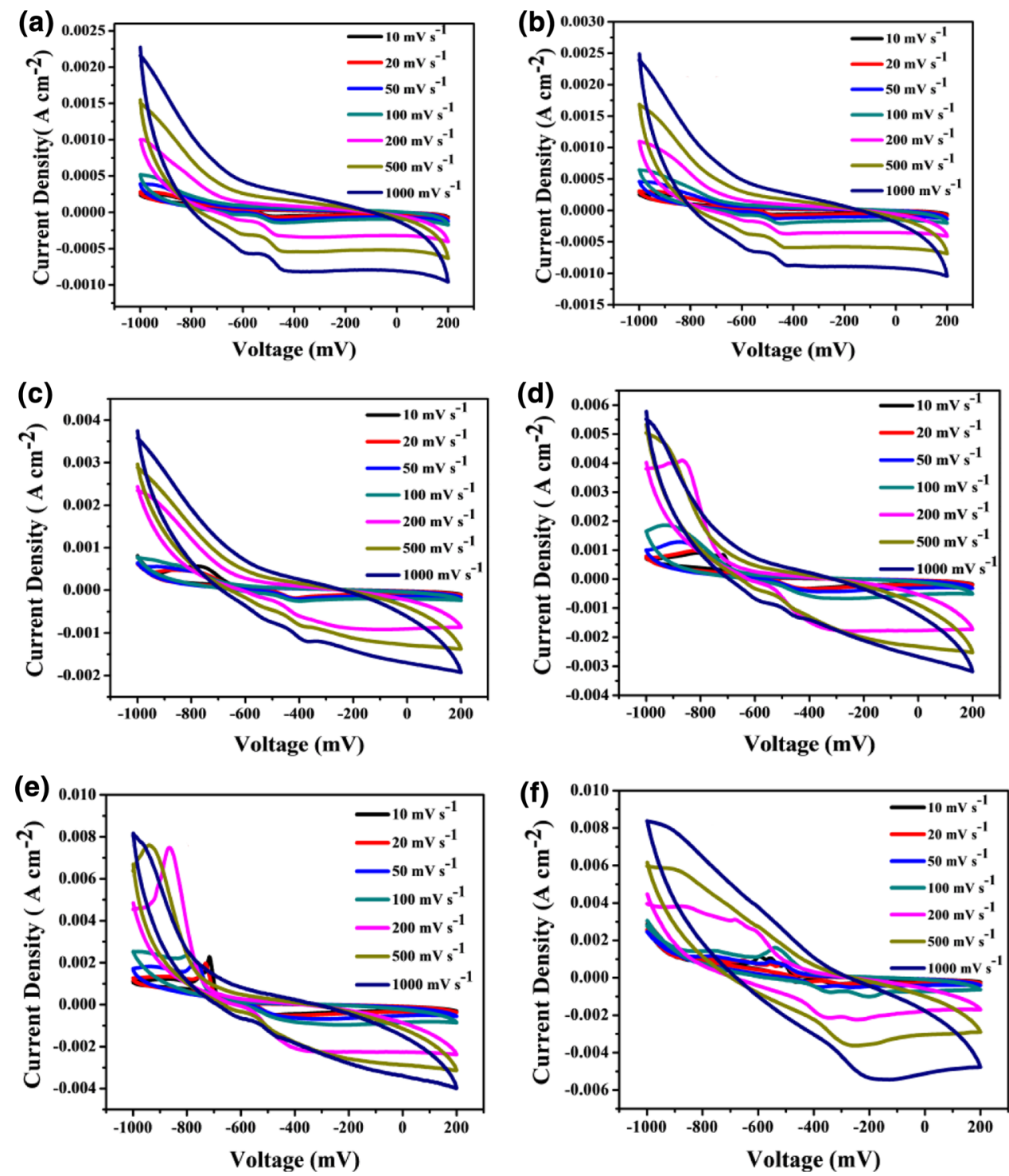

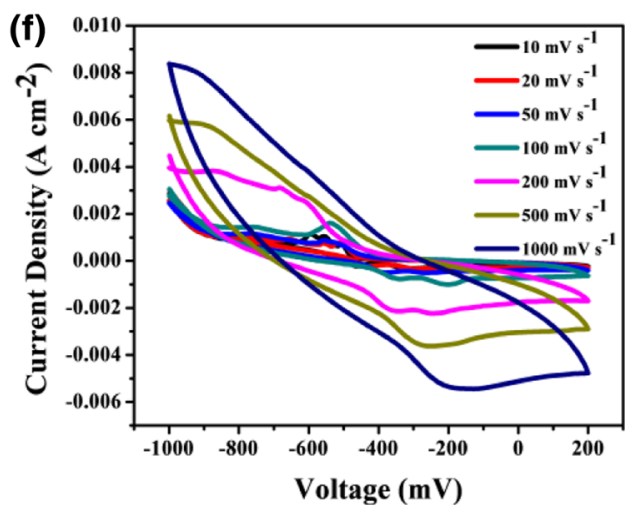

on their corresponding GCD curves and are plotted in Fig. 7c. The specific capacitance values were 72.2, 54.0, $41.5,36.3,33.0,30.0$, and $26.7 \mathrm{~F} \mathrm{~g}^{-1}$ at the current densities of $1,2,3,5,10,15$, and $20 \mathrm{~A} \mathrm{~g}^{-1}$, respectively. These excellent performances could be attributed to the nanoflakes and high specific surface areas which facilitated fast ion transfer by enhancing redox faradic reactions. This indicates that about $37 \%$ of capacitance still remained as the current density increased from 1 to $20 \mathrm{~A} \mathrm{~g}^{-1}$, suggesting the superb rate capability. Figure $7 d$ shows the cycling stability of the as-prepared BFO nanoflake-type electrodes by conducting charge/discharge tests at a current density of $5 \mathrm{~A} \mathrm{~g}^{-1}$ for 1500 cycles. The specific capacitance of the BFO electrode maintained $82.8 \%$ of its initial value, indicating a good stability. The charge-discharge curves of the final 10 cycles are shown in the inset of Fig. $7 d$, showing almost the same symmetric shape, which implies that the BFO electrode remain unchanged for significant structural change during the charge/discharge processes.

The EIS measurement of the BFO electrode obtained after air annealing at $600{ }^{\circ} \mathrm{C}$ is presented in Fig. 7e. Capacitance can be interpreted as a measure for electrode activity, surface coverage, and the state-of-charge of an energy storage. The frequency response of capacitance reflects the amount of the surface area accessible to the electrolyte. Capacitance at high-frequency region shows the outer surface, which may depend on grain boundaries and other interparticle phenomena. Capacitance at low frequencies highlights the inner surface, which is primarily determined by the pore-size distribution and the speed of ion transport through the porous electrode (Qin et al. 2011). The plot at the high-frequency side was parallel to the $\mathrm{X}$-axis whereas the subsequent regions were inclined to the $\mathrm{X}$-axis suggesting that the charge transfer resistance rates 
Fig. 7 a Effect of scan rate on $\mathrm{SC}$ value of $\mathrm{BFO}$ electrode. b Galvanostatic chargedischarge curves of the BFO at different current densities. c Specific capacitance under different current densities. d Capacitance retention for BFO at 1500 cycles. e EIS measurement of BFO electrode
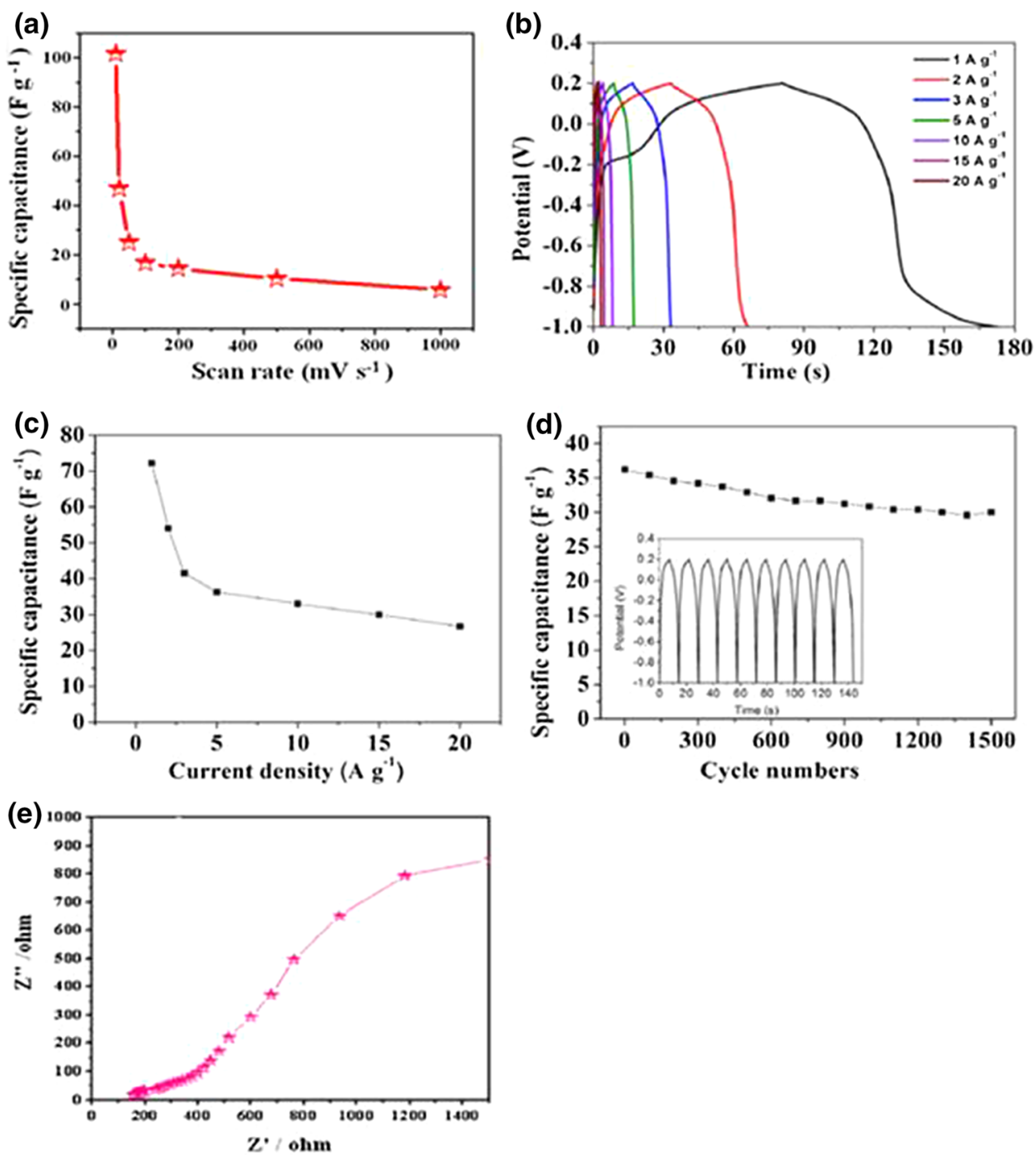

at high-frequency regions was faster than those at lowfrequency regions which could be due to an inherent property of ferrites.

\section{Conclusions}

In this study, we have demonstrated a simple and economical electrodeposition process to synthesize bismuth ferrite (BFO) for supercapacitor application. By changing the electrodeposition composition/condition, structure and morphology were greatly altered. Effects of annealing on BFO electrodes for 400,500 , and $600{ }^{\circ} \mathrm{C}$ were studied for evaluation of phase and surface morphology, if there is any. The cyclic voltammetry parameters of BFO electrodes were significantly enhanced in $\mathrm{NaOH}$ electrolytes than in other aqueous electrolytes. The maximum specific capacitance was obtained in $2 \mathrm{M} \mathrm{NaOH}$ electrolyte; therefore the same electrode was employed in the rest of the measurements. At $600{ }^{\circ} \mathrm{C}, \mathrm{BFO}$ electrodes were superhydrophilic in nature, with the lower contact angle being beneficial for achieving enhanced specific capacitance. The effect of scan rate on supercapacitive properties of annealed BFO thin-film electrode was reported. The maximum specific capacitance of electrode annealed at $600{ }^{\circ} \mathrm{C}$ using galvanostatic charge-discharge curve was found to be $72.2 \mathrm{~F} \mathrm{~g}^{-1}$ at $1 \mathrm{~A} \mathrm{~g}^{-1}$ in $2 \mathrm{M} \mathrm{NaOH}$ electrolyte.

Acknowledgments The authors wish to thank the Department of Science and Technology (DST), New Delhi, India, and the NRF, South Korea for selecting them in Indo-Korean Research Internship (IKRI) project to carry out the research for 12 months in Pusan National University, Busan, South Korea. Authors, R. S. Mane and M. Naushad, extend their gratitude to the Visiting Professor (VP) Unit of King Saud University (KSU) for the financial support.

Open Access This article is distributed under the terms of the Creative Commons Attribution 4.0 International License (http://creativecommons.org/licenses/by/4.0/), which permits unrestricted use, distribution, and reproduction in any medium, provided you give appropriate credit to the original author(s) and the source, provide a link to the Creative Commons license, and indicate if changes were made. 


\section{References}

Adachi N, Denysenkov VP, Khartsev SI, Grishin AM (2000) Epitaxial $\mathrm{Bi}_{3} \mathrm{Fe}_{5} \mathrm{O}_{12}$ (001) films grown by pulsed laser deposition and reactive ion beam sputtering techniques. J Appl Phys 88:2734

Athoue L, Moser F, Dugas R, Crosnier O, Belanger D, Brousse T (2008) Variation of the $\mathrm{MnO}_{2}$ birnessite structure upon charge/ discharge in an electrochemical supercapacitor electrode in aqueous $\mathrm{Na}_{2} \mathrm{SO}_{4}$ electrolyte. J Phys Chem C 112:7270

Bernardo MS, Jardiel T, Peiteado M, Caballero AC, Villegas M (2011) Reaction pathways in the solid state synthesis of multiferroic $\mathrm{BiFeO}_{3}$. J Europ Ceram Soc 31:3047

Biasotto G, Simoes AZ, Foschini CR, Zaghete MA, Varela JA, Longo E (2011) Microwave-hydrothermal synthesis of perovskite bismuth ferrite nanoparticles. Mater Res Bull 46:2543

Brezesinski T, Wang J, Polleux J, Dunn B, Tolbert SH (2009) Templated nanocrystal-based porous $\mathrm{TiO}_{2}$ films for next-generation electrochemical capacitors. J Am Chem Soc 131(5):1802

Chen C, Cheng J, Yu S, Che L, Meng Z (2006) Hydrothermal synthesis of perovskite bismuth ferrite crystallites. J Cryst Growth 291:135

Chen Z, Augustyn V, Jia X, Xiao Q, Dunn B, Lu Y (2012) Highperformance sodium-ion pseudocapacitors based on hierarchically porous nanowire composites. ACS Nano 6:4319

Cheong SW, Mostovoy M (2007) Multiferroics: a magnetic twist for ferroelectricity. Nat Mater 6:13

Chu S, Majumdar A (2012) Opportunities and challenges for a sustainable energy future. Nature 488:294

Conway BE, Pell WG (2002) Power limitations of supercapacitor operation associated with resistance and capacitance distribution in porous electrode devices. J Power Sources 105:169

Das R, Khan GG, Varma S, Mukherjee GD, Mandal K (2013) Effect of quantum confinement on optical and magnetic properties of Pr-Cr-Codoped bismuth ferrite nanowires. J Phys Chem C 117(39):20209

David A, Tompsett C, Parker CS, Islam MS (2014) Rutile ( $\beta$-) $\mathrm{MnO}_{2}$ surfaces and vacancy formation for high electrochemical and catalytic performance. J Am Chem Soc 136(4):1418

Dutta N, Bandyopadhyay SK, Rana S, Sen P, Himanshu AK (2013) Remarkably high value of capacitance in $\mathrm{BiFeO} 3$ Nanorod, Cornell University Library. arXiv 1309:5690

Gao F, Yuan Y, Wing KF, Chen XY, Chen F, Liu JM, Ren ZF (2006) Preparation and photoabsorption characterization of $\mathrm{BiFeO}_{3}$ nanowires. Appl Phys Lett 89:102506

Gujar TP, Shinde VR, Kulkarni SS, Pathan HM, Lokhande CD (2006) Room temperature electrodeposition and characterization of bismuth ferric oxide (BFO) thin films from aqueous nitrate bath. App Surf Sci 252:3585

Jadhav VV, Patil SA, Shinde DV, Waghmare SD, Zate MK, Mane RS, Han SH (2013) Hematite nanostructures: morphologymediated liquefied petroleum gas sensors. Sens Actuators B Chem. 188:669

Jaiswal A, Das R, Maity T, Vivekanand K, Adyanthaya S, Poddar P (2010) Temperature- dependent raman and dielectric spectroscopy of $\mathrm{BiFeO}_{3}$ nanoparticles: signatures of spin-phonon and magnetoelectric coupling. J Phys Chem C 114(29):12432

Kang J, Hirata A, Kang L, Zhang X, Hou Y, Chen L, Li C, Fujita T, Akagi K, Chen M (2013) Self-grown oxy-hydroxide@ nanoporous metal electrode for high-performance supercapacitors. Angew Chemie 52:1664

Kumar MM, Palkar VR, Srinivas K, Suryanarayana SV (2000) Ferroelectricity in a pure $\mathrm{BiFeO}_{3}$ ceramic. Appl Phys Lett 76:1

Kuo HY (2013) Effective property of multiferroic fibrous composites with imperfect interfaces. Smart Mater Struct 22:105005
Lang X, Hirata A, Fujita T, Chen M (2011) Nanoporous metal/oxide hybrid electrodes for electrochemical supercapacitors. Nat Nanotechnol 6:232

Liang Y, Schwab MG, Zhi L, Mugnaioli E, Kolb U, Feng X, Mullen K (2010) Direct access to metal or metal oxide nanocrystals integrated with one-dimensional nanoporous carbons for electrochemical energy storage. J Am Chem Soc 132(42):15030

Liu M, Gan L, Xiong W, Xu Z, Zhu D, Chen L (2014) Development of $\mathrm{MnO}_{2}$ /porous carbon microspheres with a partially graphitic structure for high performance supercapacitor electrodes. J Mater Chem A 2:2555

Lokhande CD, Gujar TP, Shinde VR, Mane RS, Han SH (2007) Electrochemical supercapacitor application of pervoskite thin films. Electrochem Comm 9:1805

Luo Y, Kong D, Luo J, Wang Y, Zhang D, Qiu K, Cheng C, Ming C, Ting Li (2014) Seed-assisted synthesis of $\mathrm{Co}_{3} \mathrm{O}_{4} @ \alpha-\mathrm{Fe}_{2} \mathrm{O}_{3}$ core-shell nanoneedle arrays for lithium-ion battery anode with high capacity. RSC Adv. 4:13241

Mane RS, Lokhande CD, Todkar VV, Chung H, Yoon MY, Han SH (2007) Photosensitization of nanocrystalline $\mathrm{TiO}_{2}$ film electrode with cadmium sulphoselenide. Appl Surf Sci 253:3922

Martin LW (2010) Engineering functionality in the multiferroic $\mathrm{BiFeO}_{3}$ controlling chemistry to enable advanced applications. Dalton Trans 39:10813

Mo Y, Antonio MR, Scherson DA (2000) In situ Ru K-edge X-Ray absorption fine structure studies of electroprecipitated ruthenium dioxide films with relevance to supercapacitor applications. J Phys Chem B 104:9777

Mohan S, Subramanian B (2013) Nanostructured $\mathrm{Bi}_{(1-x)} \mathrm{Gd}_{(x)} \mathrm{FeO}_{3}$ a multiferroic photocatalyst on its sunlight driven photocatalytic activity. RSC Adv. 3:23737

Niesen TP, De Guire MR (2001) Review: deposition of ceramic thin films at low temperatures from aqueous solutions. J Electroceram 6:169

Palkar VR, Pinto R (2002) BiFeO3 thin films: novel effects. Pramana J Phys. 58:1003

Perejon A, Sanchez-Jimenez PE, Criado Jose M, Perez-Maqueda LA (2014) Thermal stability of multiferroic $\mathrm{BiFeO}_{3}$ : kinetic nature of the $\beta-\gamma$ transition and peritectic decomposition. J Phys Chem C 118(45):26387

Petzold J (2003) Applications of nanocrystalline softmagnetic materials for modern electronic devices. Scripta Mater 48:895

Qin H, Zhang H, Zhang BP, Xu L (2011) Hydrothermal synthesis of perovskite $\mathrm{BiFeO}_{3}-\mathrm{BaTiO}_{3}$ crystallites. J Am Ceram Soc 94(11):3671

Sartale SD, Lokhande CD, Giersig M, Ganesan V (2004) Novel electrochemical process for the deposition of nanocrystalline $\mathrm{NiFe}_{2} \mathrm{O}_{4}$ thin films. J Phys Condens Matter 16:773

Sathiya M, Prakash AS, Ramesha K, Tarascon JM, Shukla AK (2011) $\mathrm{V}_{2} \mathrm{O}_{5}$-anchored carbon nanotubes for enhanced electrochemical energy storage. J Am Chem Soc 133:16291

Schileo G (2013) Recent developments in ceramic multiferroic composites based on core/shell and other heterostructures obtained by sol-gel routes. Prog Solid State Chem 41:87

Singh VR, Dixit A, Garg A, Agrawal DC (2008) Effect of heat treatment on the structure and properties of chemical solution processed multiferroic BiFeO3 thin films. Appl Phys A 90:197

Subramanian V, Hall SC, Smith PH, Rambabu B (2004) Mesoporous anhydrous $\mathrm{RuO} 2$ as a supercapacitor electrode material. Solid State Ionics 175:511

Sun R, Nakajima A, Fujishima A, Watanabe T, Hashimoto K (2001) Photoinduced surface wettability conversion of $\mathrm{ZnO}$ and $\mathrm{TiO} 2$ thin films. J Phys Chem B 105:1984

Waghmare SD, Jadhav VV, Gore SK, Yoon SJ, Ambade SB, Lokhande BJ, Mane RS, Han SH (2012) Efficient gas sensitivity 
in mixed bismuth ferrite micro (cubes) and nano (plates) structures. Mater Res Bull 47:4169

Wang YP, Zhou L, Zhang MF, Chen XY, Liu JM, Liu ZG (2004) Room-temperature saturated ferroelectric polarization in $\mathrm{BiFeO}_{3}$ ceramics synthesized by rapid liquid phase sintering. Appl Phys Lett $84: 1731$

Wang G, Zhang L, Zhang J (2012) A review of electrode materials for electrochemical supercapacitors. Chem Soc Rev 41:797

Wang L, Ji H, Wang S, Kong L, Jiang X, Yang G (2013) Preparation of $\mathrm{Fe}_{3} \mathrm{O}_{4}$ with high specific surface area and improved capacitance as a supercapacitor. Nanoscale 5:3793

Winter M, Brodd RJ (2004) What are batteries, fuel cells, and supercapacitors? Chem Rev. 104:4245

Xia X, Zhang Y, Chao D, Guan C, Zhang Y, Li L, Ge X, Bacho IM, Tu J, Fan HJ (2014) Solution synthesis of metal oxides for electrochemical energy storage applications. Nanoscale 6:5008

Xie SH, Li JY, Proksch R, Liu YM, Zhou YC, Liu YY, Pan LN, Qiao $\mathrm{Y}$ (2008) Nanocrystalline multiferroic $\mathrm{BiFeO}_{3}$ ultrafine fibers by sol-gel based electrospinning. Appl Phys Lett 93:222904
Yan J, Khoo E, Sumboja A, Lee PS (2010) Facile coating of manganese oxide on tin oxide nanowires with high-performance capacitive behavior. ACS Nano 4:4247

Yoshimura M, Suchanek WL, Byrappa K (2000) Soft solution processing: a strategy for one- step processing of advanced inorganic materials. Mater Res Soc Bull 25:17

$\mathrm{Yu} \mathrm{L}$, Zhang L, Bin Wu H, Wen Lou X (2014) Formation of $\mathrm{Ni} x \mathrm{Co}_{3} \_x \mathrm{~S}_{4}$ hollow nanoprisms with enhanced pseudocapacitive properties, Angew. Chemie 126:3785

Zhai Y, Dou Y, Zhao D, Fulvio PF, Mayes RT, Dai S (2011) Carbon materials for chemical capacitive energy storage. Adv Mater 23:4828

Zheng H, Liu X, Diao C, Gu Y, Zhang W (2012) A separation mechanism of photogenerated charges and magnetic properties for $\mathrm{BiFeO}_{3}$ microspheres synthesized by a facile hydrothermal method. Phys Chem Chem Phys 14:8376 